\title{
Correction to: Numerical Analysis of Shock Wave Diffraction
}

Arnab Chaudhuri, Gustaaf B. Jacobs, and Xiao Hong

\section{Correction to:}

Chapter 146 in: A. Sasoh et al. (eds.), 31st International Symposium on Shock Waves 1, https://doi.org/10.1007/978-3-319-91020-8_146

The original version of this chapter was inadvertently published with incorrect affiliation of the second author. The correct information is given below:

G. B. Jacobs, Department of Aerospace Engineering \& Engineering Mechanics, San Diego State University, San Diego, CA, USA

This has been updated in the chapter. 